\title{
Assessing the Needs to Incorporate Completion Details in a Petroleum Reservoir Simulation Model
}

\author{
Liang-Biao Ouyang*
}

Chevron Corporation, P. O. Box 5095, Bellaire, TX 77402-5095, USA

\begin{abstract}
Most of the current research and commercial reservoir simulators lack the capability to handle complex completion details like perforation tunnels in a simulation study. In most common applications, the simplified handling of completion complexity in reservoir simulations is not expected to introduce significant error in simulation results. However, it has been found that under certain circumstances, especially in high rate wells that have become more and more common in deepwater oil and profilic gas development, exclusion of the complex completion details in a reservoir simulation model would lead to nontrivial errors. New equations have been proposed to assess the needs to incorporate completion details in a reservoir simulation study based on the understanding of the fluid flow in a formation, the fluid flow along a wellbore and the fluid flow through perforation tunnels if exist. A series of sensitivity studies with different completion options under different flow and reservoir environments has been conducted to provide some guidance to improve well performance prediction through reservoir simulation. Impacts of key parameters like perforation density, perforation diameter, perforation length, wellbore length, borehole diameter, well completion configuration, well placement, reservoir permeability, reservoir heterogeneity, pressure drawdown, etc, have also been investigated.
\end{abstract}

Keywords: Frictional pressure drop, horizontal wells, non-darcy flow, perforation tunnels, reservoir simulation, well completion.

\section{INTRODUCTION}

As one of the most critical well components, well completion is expected to have a significant impact on the performance of a well. Over the past decade, oil and gas industry has moved towards several new frontier areas, like deepwater, ultradeep water, high rate oil/gas wells, and so on. As a result, a number of new advanced well completion options have been developed and applied in different fields in the world [1].

For a majority of new field developments, well completion takes a substantial chunk in the whole CAPEX for a new well. Well completion cost could vary significantly from one completion type to the other, so could the impact on the performance of the well. Therefore, an appropriate selection of a well completion is anticipated to lead to an efficient well completion design, cost saving, as well as an improved well performance. To successfully select the right well completion, a well completion design based on comprehensive study of fluid (oil, gas, water) flow and solid (sand, fine, scale, completion debris, etc) movement along different portions of a well completion is required. Unfortunately, the details of well completion are normally not taken into account in most of the current reservoir simulators [2].

While the ignorance of completion details in a reservoir simulation model may not lead to much error in production prediction for some wells, it could result in significant overestimate of well production for some other wells. The

*Address correspondence to this author at the Chevron Corporation, P. O. Box 5095, Bellaire, TX 77402-5095, USA; Tel: +61 89485 5587;

E-mail: louy@chevron.com question that has been asked over and over again is: when the complex completion details/specifics should be considered in a reservoir simulation study in the first place? To provide answers and/or guidance to the question is the key objective of the present paper.

Firstly, complexity in a well completion will be briefly addressed. Secondly, the fluid flow inside a wellbore, the fluid flow in a reservoir, as well as the fluid flow along each perforation tunnel, if existent, will be discussed, which lead to new equations that can be applied to quickly evaluate the needs to consider completion details in a reservoir simulation study. Thirdly, a series of sensitivity studies with different completion options under different flow and reservoir environments will be presented. Impacts of key parameters like fluid property, wellbore geometry, wellbore length, wellbore diameter, well completion configuration, well placement, reservoir permeability, reservoir heterogeneity, pressure drawdown, etc. will be evaluated.

\section{COMPLETION COMPLEXITY}

For any new wells, the first step in well completion design is to pick the well completion type from a number of available options. The completion selection can be a complex process that typically involves cost estimate, production efficiency, completion efficiency (well skin), and the ability to handle any potential flow complexity such as sand production, water coning / cresting, gas and/or water shut-off. The cost may vary significantly from one completion type to the other; and the production efficiency and completion efficiency changes depending on the well and flow conditions [1]. 


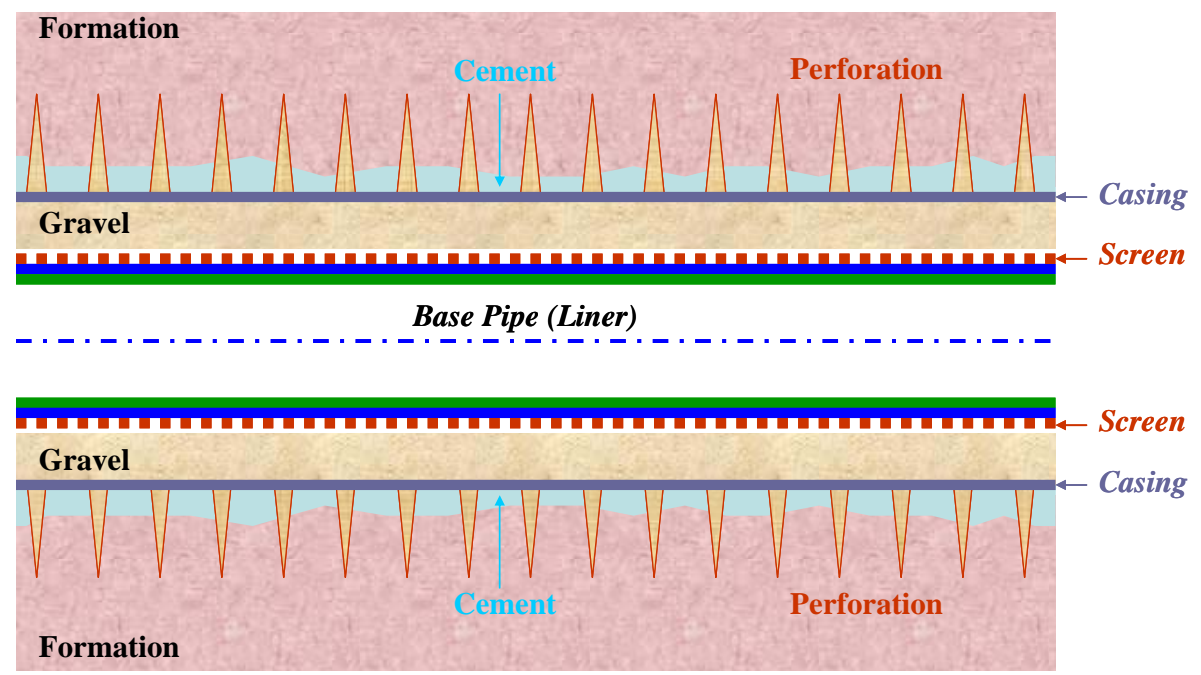

Fig. (1). Illustration of a cased-hole completion for horizontal wells.

Openhole gravel pack, pre-drilled liner, cased-hole gravel pack, standalone sand screen, cased-hole frac pack, expandable sand screen (ESS), and others, are among the most widely-implemented well completion options considered for a new well.

For reference, Fig. (1) illustrates a schematic for a typical cased-hole gravel pack well completion. It can be seen that there are many fine details in the completion (like base pipe, gravel, cement, screen, annulus, perforation tunnels, and so on) that would be easily ignored in building a typical reservoir simulation model. Under a majority of reservoir simulation studies, the well would simply be treated as a borehole with appropriate nominal diameter; at the same time, a skin may also be introduced to represent formation damage or improvement in flow environment in the neighborhood of the well.

Note that for simple completion options, like openhole completion without any perforation, the wellbore used in a reservoir simulation model would fit perfectly to the actual wellbore. Fluid flow would flow from reservoir to wellbore (borehole) and then to the wellhead. This type of completion is what is represented in a typical reservoir simulation model. So there are no needs to worry about the completion in reservoir simulation.

Nevertheless, for most wells, well completion would be much more complex than an openhole wellbore without any perforation. Therefore, it may be necessary to consider completion details in order to appropriately predict well production through reservoir simulation. Indeed, it would be too cumbersome if not complicated to include all the completion details in a reservoir simulation because there are too many flow paths (some of them could be quite trivial depending on the flow conditions) involved. For example, for the completion defined in Fig. (1), the following flow paths exist:

- Fluid flow inside the base pipe (liner);

- Fluid flow from annulus to the base pipe through the screen;

- Fluid flow from the base pipe to the annulus through screen, which does happen in certain wells due to irregu- lar pressure distribution inside the base pipe and along the annulus;

- Fluid flow inside the annulus between screen and casing;

- Fluid flow through perforation tunnels;

- Convergent flow from formation into each perforation tunnel.

For most wells, all the flows listed above should cause trivial pressure drop as compared to the pressure drawdown from the reservoir to the wellbore. Unfortunately, this is not always the case. For example, for a high rate horizontal well, the wellbore pressure drop could be significant, and the pressure drop along perforation tunnels could also be substantial. Therefore, there is a need to tell when all the completion details should be considered to appropriately predict well production and evaluate well performance by means of a reservoir simulator.

\section{PRESSURE DRAWDOWN FOR FLOW IN A RES- ERVOIR}

As mentioned before, the fluid flow inside a wellbore and the fluid flow along perforation tunnels may be substantial as compared to the anticipated pressure drawdown. To compare the relative importance of these pressure drops, the simplified homogeneous but anisotropic parallelepiped reservoir as shown in Fig. (2) is introduced. The reservoir has dimensions $2 \mathrm{x}_{\mathrm{e}}, 2 \mathrm{y}_{\mathrm{e}}, \mathrm{h}$ in $\mathrm{x}, \mathrm{y}$, and $\mathrm{z}$ directions, respectively and its outer boundaries can be either constant pressure or impermeable. A horizontal well with length $\mathrm{L}$ is completed in the reservoir.

To simplify the problem, the following additional assumptions are made:

- Formation properties are independent of pressure.

- Reservoir fluid is single-phase and either incompressible or slightly compressible with a constant compressibility.

With the assumptions, the governing equation can be written as [3]: 


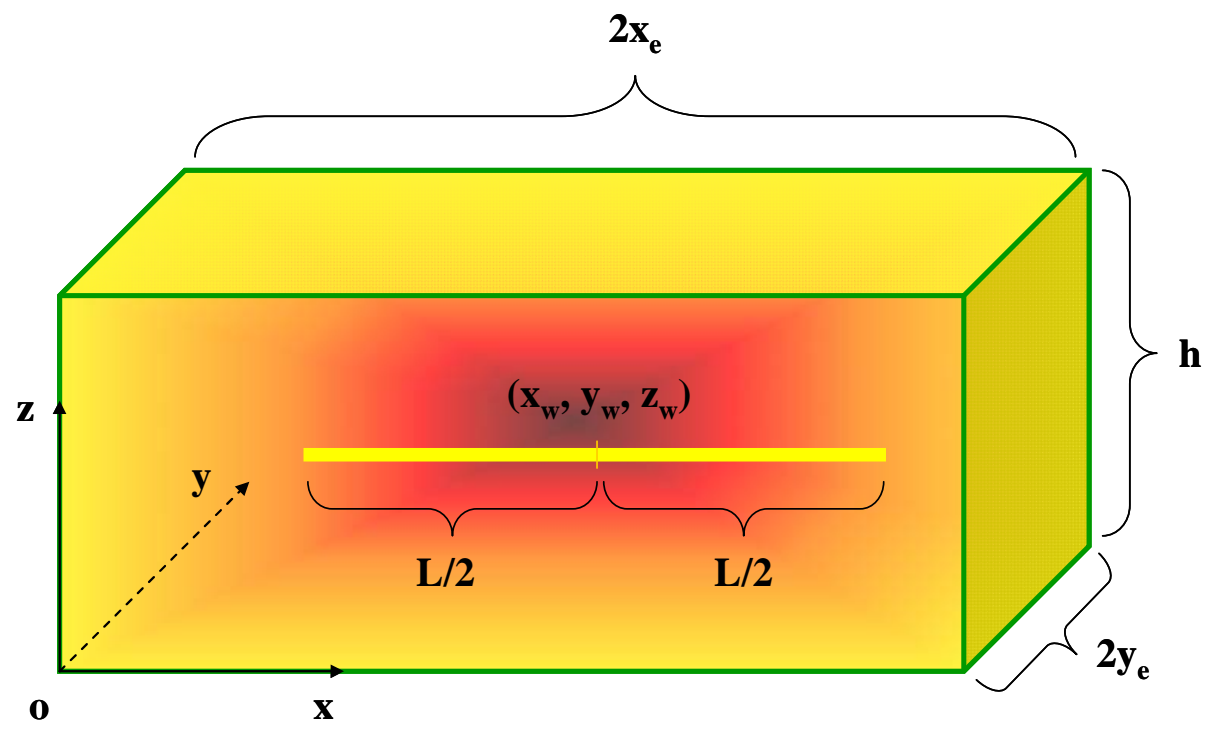

Fig. (2). Schematics of a horizontal well in a parallelepiped reservoir.

$k_{x} \frac{\partial^{2} \phi}{\partial x^{2}}+k_{x} \frac{\partial^{2} \phi}{\partial y^{2}}+k_{x} \frac{\partial^{2} \phi}{\partial z^{2}}=\varphi \mu c_{t} \frac{\partial \phi}{\partial t}$

where $\varphi$ is the fluid potential that is related to reservoir pressure by:

$\phi=p+\int \frac{g}{g_{c}} \rho d z=p+\frac{g}{g_{c}} \rho z$

The solution for Eq. 1 can be expressed as the following relationship:

$\Delta p=Q / J_{H}$

The productivity index (PI or $\mathrm{J}_{\mathrm{H}}$ ) depends on the type of fluid (oil or gas), the type of well orientation (horizontal, slanted or vertical wells), and the reservoir outer boundary conditions (constant pressure or impermeable).

For horizontal oil producers, the productivity index (PI or $\mathrm{J}_{\mathrm{H}}$ ) under steady-state flow conditions can be evaluated by the modified Joshi $[4,5]$ solution:

$$
J_{H}=\frac{0.007078 k_{h} h / \mu_{o} B_{o}}{\ln \left[\frac{a+\sqrt{a^{2}-(L / 2)^{2}}}{L / 2}\right]+\ln \left(\frac{h}{2 r_{w}}\right) \frac{\alpha^{2} h}{L}}
$$

where:

$a=0.5 L \sqrt{0.5+\sqrt{0.25+\left(2 r_{e h} / L\right)^{4}}}$

For gas wells:

$$
J_{H}=\frac{0.0007027 k_{h} h\left(p_{r}+p_{w f}\right) / \mu_{g} Z T}{\ln \left[\frac{a+\sqrt{a^{2}-(L / 2)^{2}}}{L / 2}\right]+\ln \left(\frac{h}{2 r_{w}}\right) \frac{\alpha^{2} h}{L}}
$$

Note that other methods, like Borisov [6], Giger [7], Giger [8], Renard \& Depuy [9], may also be used to estimate the PI; however, the difference in the predicted PIs is not expected to be significant.
For pseudo-steady state flow, the pressure drawdown through formation can be determined by using the Babu \& Odeh [10] solution for a horizontal oil producer:

$$
J_{H}=\frac{0.007078\left(2 x_{e}\right) \sqrt{k_{y} k_{v}}}{\mu_{o} B_{o}\left[\ln \left(\sqrt{A_{1}} / r_{w}\right)+\ln C_{H}-0.75+s_{R}\right]}
$$

where $\mathrm{C}_{\mathrm{H}}$ represents the shape factor for a horizontal well, and the value $S_{R}$ accounts for the skin factor due to partial penetration of the horizontal well in the aerial plane [11]. $\mathrm{A}_{1}$ is the horizontal well drainage area in the vertical plane, or, $\mathrm{A}_{1}=2 \mathrm{y}_{\mathrm{e}} \mathrm{h}$. The equations for the calculation of the $\mathrm{C}_{\mathrm{H}}$ and $\mathrm{s}_{\mathrm{R}}$ can be found in Babu \& Odeh [10] or Joshi [11].

In addition to $\mathrm{Babu} \&$ Odeh [10], there are other solutions, like those by Mutalik [12] and Kuchuk [13], that can be applied in determining the pressure drawdown or production rate of a horizontal well.

For a horizontal gas producer:

$$
J_{H}=\frac{0.0007027\left(2 x_{e}\right) \sqrt{k_{y} k_{v}}\left(p_{r}+p_{w f}\right)}{\mu_{g} Z T\left[\ln \left(\sqrt{A_{1}} / r_{w}\right)+\ln C_{H}-0.75+s_{R}+D Q\right]}
$$

where $\mathrm{D}$ is the non-Darcy coefficient for fluid flow in the formation and can be calculated by the following equation:

$$
D=2.222 \times 10^{-15} \frac{\gamma_{g} k h \beta}{\mu r_{w} h^{2}}
$$

and the Forchheimer coefficient $\beta$ (in $1 / \mathrm{ft}$ ) can be determined by an appropriate correlation such as the following correlation proposed by Firoozabadi \& Katz [14]:

$$
\beta=\frac{2.73 \times 10^{10}}{k^{-1.1045}}
$$

where the permeability $\mathrm{k}$ should be in $\mathrm{mD}$.

Note that there are a number of correlations that have been developed and reported in the literature for the calculation of the Forchheimer coefficient [15]. The predicted 
Forchheimer coefficient based on different correlations can vary significantly as clearly illustrated in Fig. (3) below.

\section{FLUID FLOW ALONG A WELLBORE}

The frictional pressure drop along a wellbore of an oil production well is not expected to exceed the value estimated by the following relationship:

$\Delta P_{w}=f \frac{\rho V^{2} L}{r_{w}}=f \frac{\rho Q^{2} B_{o}^{2} L}{\pi r_{w}^{5}}$

where the Fanning friction factor (f) can be determined via the following Colebrook-White [16] correlation:

$$
f=\left\{\begin{array}{cr}
\frac{16}{R_{e}} & \text { when } R_{e} \leq 2200 \\
0.0625\left[\log \left(\frac{\varepsilon}{7.4 r_{w}}+\frac{1.255}{R_{e} f^{0.5}}\right)\right]^{-2} \text { when } & R_{e}>2200
\end{array}\right.
$$

where $R_{e}$ is the Reynolds number.

For gas wells, the general integrated flow equation presented by Ouyang \& Aziz [17] can be used to estimate the pressure drop from the toe to the heel of a horizontal well:

$$
\Delta p_{w}=6.3208 \times 10^{-12} \frac{f \gamma_{g} Z T L Q^{2}}{r_{w}^{5} p_{w f}}
$$

where Q is the gas rate in Mscf/day, $p_{w f}$ is the bottomhole wellbore pressure in psia, $\mathrm{L}$ is the pipe length in feet, $\mathrm{T}$ is the average wellbore temperature in ${ }^{\circ} \mathrm{R}$, and $\mathrm{r}_{\mathrm{w}}$ is the wellbore radius in feet.

\section{FLUID FLOW ALONG A PERFORATION TUNNEL}

As clearly demonstrated by Nguyen's experiment [18] (Fig. 4), the fluid flow may experience the substantial pressure drop along a perforation tunnel as compared to the pressure drop in the convergence zone. It has been found that the pressure drops along the perforation tunnels can be up to 2 5 times the amount across the convergence zone. Production data from various fields has demonstrated that the pressure drops along the perforation tunnels can be much higher than the pressure drop along a wellbore.

Fluid flow along a perforation tunnel is normally treated as a linear flow in a porous pipe filled with high permeability gravels. For oil well, the following equations can be applied to estimate the amount of pressure drop along a perforation tunnel [19]:

$$
\Delta p_{p t}=0.888 \frac{L_{p} \mu_{o}}{k_{g}} \frac{Q}{n_{p} L A_{p}}+9.1 \times 10^{-13} \beta L_{p} \rho\left(\frac{Q}{n_{p} L A_{p}}\right)^{2}
$$

The first term in the r.h.s. of Eq. 13 represents the Darcy flow in the perforation tunnel, whereas the second term represents the non-Darcy flow in the tunnel. For a majority of wells in the world, horizontal permeability is expected to be lower than $250 \mathrm{mD}$, as a result, the non-Darcy component would be much smaller than the Darcy flow component as shown in Fig. (5).

For gas wells:

$$
\Delta p_{p t}=p_{w f}-\left\{p_{v f}^{2}-\frac{0.2462 Z T \mu_{g} L_{p} Q}{n_{p} L d_{p}^{2}} \cdot\left(\frac{1}{k_{g}}+\frac{2.57 \times 10^{-12} Q \beta \gamma_{g}}{\mu_{g} n_{p} L d_{p}^{2}}\right)\right\}^{0.5}
$$

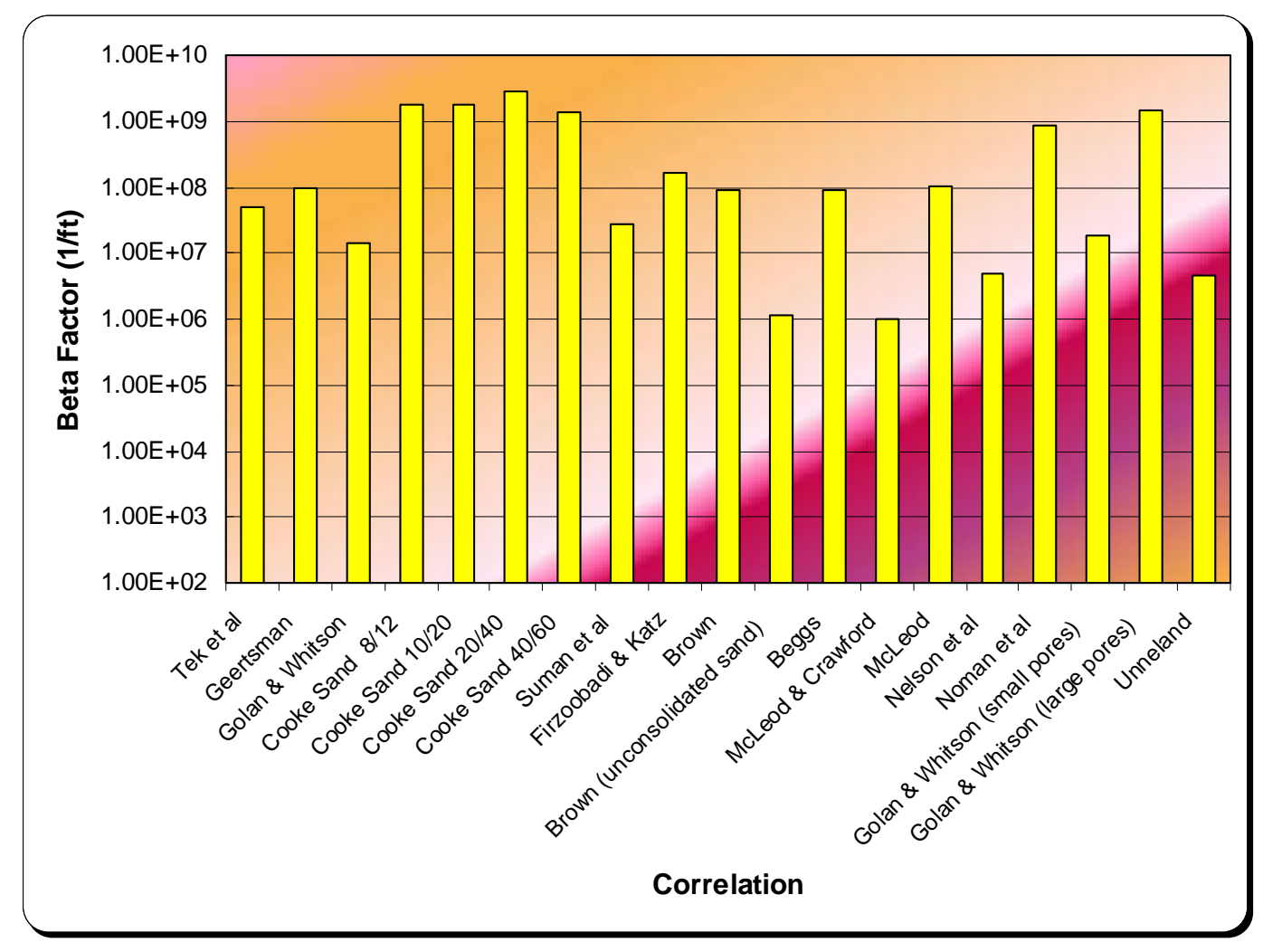

Fig. (3). The forchheimer coefficient from different correlations for formation sands. 


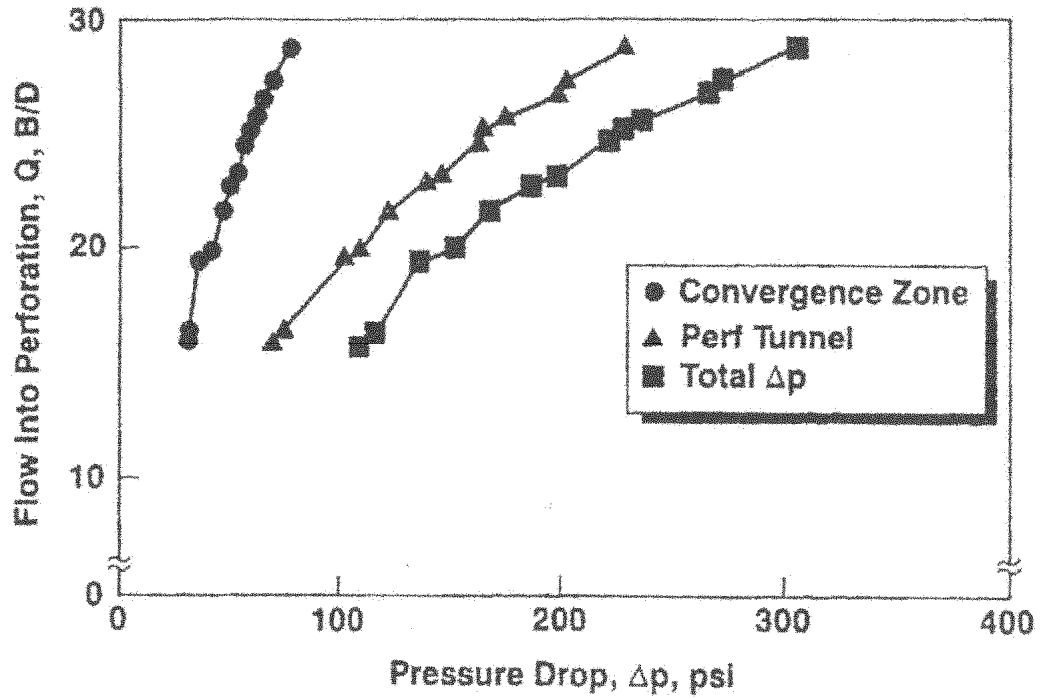

Fig. (4). Pressure drops along a perforation tunnel (after Nguyen, 1986).

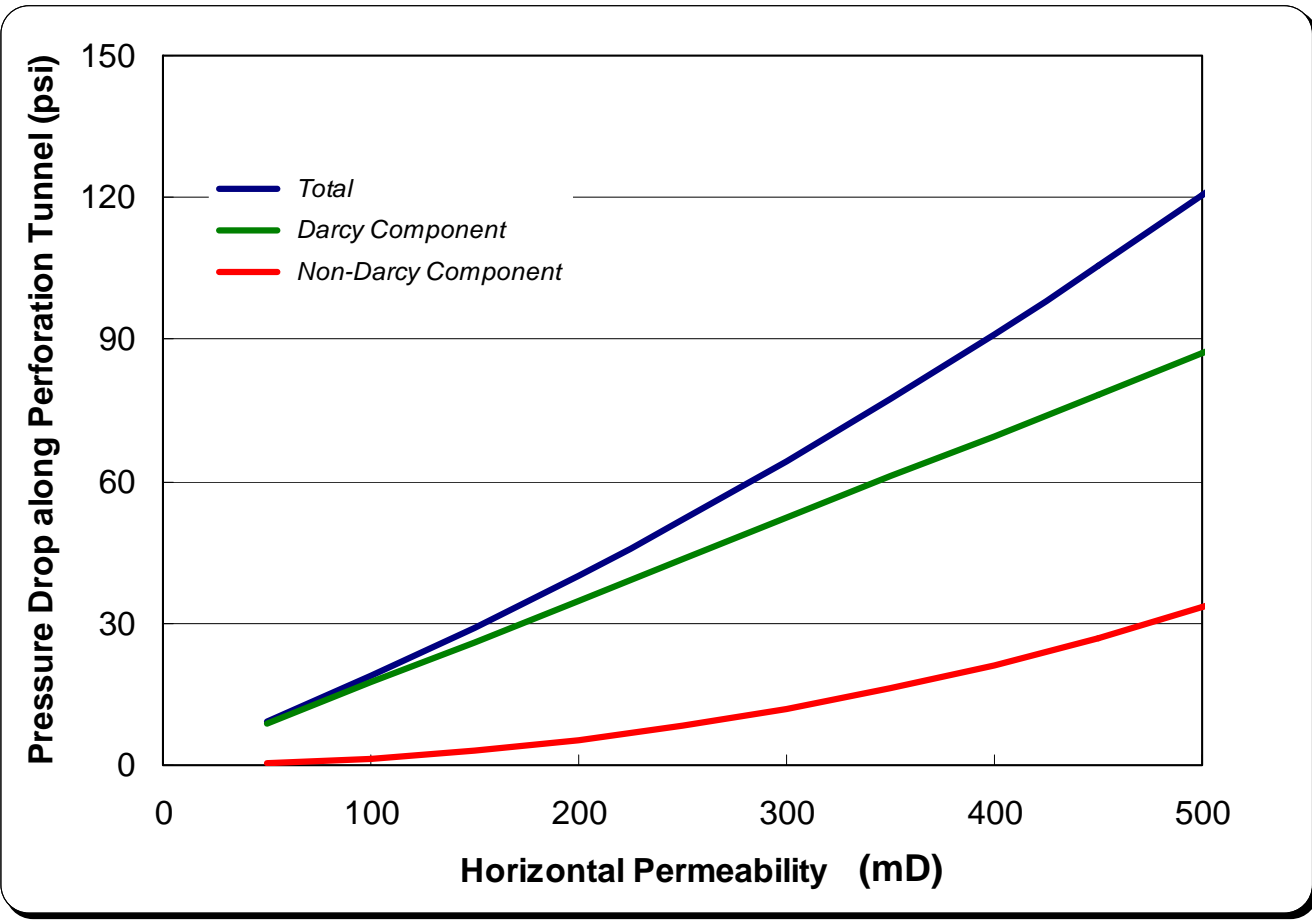

Fig. (5). Pressure drop components in a perforation tunnel.

where the pressure at the inlet of the tunnel (formation side) has been approximated by the bottomhole wellbore pressure $\mathrm{p}_{\mathrm{wf}}$. The approximation is not expected to introduce much error in the pressure drop prediction.

Similar to the fluid flow in a formation, there are many different correlations proposed for estimating the Forchheimer coefficient $\beta$ for fluid flow along a perforation tunnel. A list of the correlations can be found in LopezHernandez [20]. Once again, the prediction of the Forchheimer coefficient varies significantly from one correlation to the other (Fig. 6). Therefore, it is critical to select a correlation that applies to the flow conditions under investigation. It is highly recommended that laboratory data should be collected and applied to validate and determine the most appropriate Forchheimer coefficient correlation for a particular field.

\section{THE PROPOSED CRITERIA}

Based on field experience, the following criteria have been proposed to determine when a detailed completion should be incorporated into a reservoir simulation model to minimize the error in prediction:

a. The frictional wellbore pressure drop is equal to or larger than $10 \%$ of the pressure drawdown; and/or,

b. The pressure drops along perforation tunnels if exist should be equal to or larger than $10 \%$ of the pressure drawdown; 


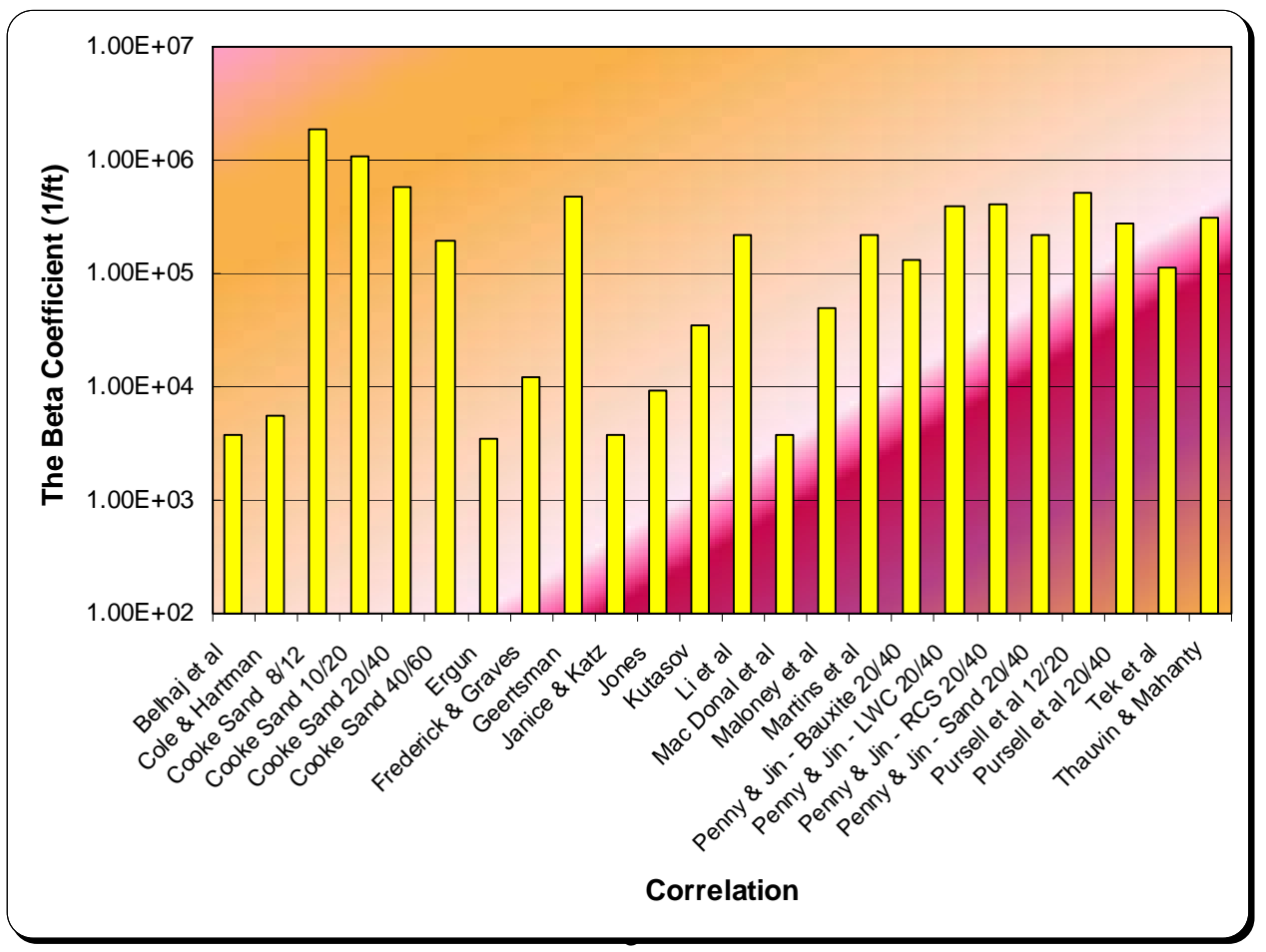

Fig. (6). The forchheimer coefficient from different correlations for gravels.

For any wells in a reservoir, as long as either or both criterion listed above is satisfied, it is highly recommended that the well completion be taken into account when building up a reservoir simulation model for well performance prediction. Otherwise, significant error may be introduced in the prediction results.

Note that under certain circumstances, although neither criterion is met, the sum of the frictional wellbore pressure drop and the pressure drops along perforation tunnels is equal to or larger than $10 \%$ of the pressure drawdown. If that is the case, then it is also recommended that well completion be considered in the reservoir simulation studies.

For horizontal wells similar to the one shown in Fig. (2), the afore-mentioned criteria can be represented by the following mathematical expressions that have been derived from the equations presented in the previous three sections:

a. For oil wells located in a reservoir with constant pressure boundaries:

$$
\begin{aligned}
& 2.265 f \frac{\rho Q B_{o} L}{\pi D^{5}} \geq \frac{\mu_{o} E}{k_{h} h} \\
& 6.285 \times 10^{-2} \frac{L_{p} \mu_{o}}{k_{g} n_{p} L A_{p}}+6.44 \times 10^{-14} \frac{\beta L_{p} \rho Q}{n_{p}^{2} L^{2} A_{p}^{2}} \geq \frac{\mu_{o} B_{o} E}{k_{h} h}
\end{aligned}
$$

where:

$$
E=\left\{\ln \left[\frac{a+\sqrt{a^{2}-(L / 2)^{2}}}{L / 2}\right]+\ln \left(\frac{h}{2 r_{w}}\right) \frac{\alpha^{2} h}{L}\right\}
$$

b. For oil wells located in a reservoir without any constant pressure boundaries:

$$
\begin{aligned}
& 2.265 f \frac{\rho Q B_{o} L}{\pi D^{5}} \geq \frac{\mu_{o} G}{\left(2 x_{e}\right) \sqrt{k_{y} k_{v}}} \\
& 6.285 \times 10^{-2} \frac{L_{p} \mu_{o}}{k_{g} n_{p} L A_{p}}+6.44 \times 10^{-14} \frac{\beta L_{p} \rho Q}{n_{p}^{2} L^{2} A_{p}^{2}} \geq \frac{\mu_{o} B_{o} G}{\left(2 x_{e}\right) \sqrt{k_{y} k_{v}}}
\end{aligned}
$$

where:

$G=\ln \left(\sqrt{A_{1}} / r_{w}\right)+\ln C_{H}-0.75+s_{R}$

c. For gas wells located in a reservoir with constant pressure boundaries:

$$
\begin{aligned}
4.442 \times & 10^{-14} \frac{f \gamma_{g} Q L}{p_{w f} r_{w}^{5}} \geq \frac{\mu_{g} E}{k_{h} h} \\
p_{w f}- & \left\{p_{w f}^{2}-\frac{0.2462 Z T \mu_{g} L_{p} Q}{d_{p}^{2}} \cdot\left(\frac{1}{k_{g}}+\frac{2.57 \times 10^{-12} Q \beta \gamma_{g}}{\mu_{g} d_{p}^{2}}\right)\right\}^{0.5} \\
& \geq \frac{71.16 Q \mu_{g} Z T E}{k_{h} h p_{w f}}
\end{aligned}
$$

d. For gas wells located in a reservoir without any constant pressure boundary:

$$
\begin{aligned}
4.442 \times & 10^{-14} \frac{f \gamma_{g} Q L}{p_{w f} r_{w}^{5}} \geq \frac{\mu_{g} G}{\left(2 x_{e}\right) \sqrt{k_{y} k_{v}}} \\
p_{w f}- & \left\{p_{w f}^{2}-\frac{0.2462 Z T \mu_{g} L_{p} Q}{d_{p}^{2}} \cdot\left(\frac{1}{k_{g}}+\frac{2.57 \times 10^{-12} Q \beta \gamma_{g}}{\mu_{p}^{2}}\right)\right\}_{p}^{0.5} \\
\geq & \frac{71.16 Q \mu_{g} Z T G}{\left(2 x_{e}\right) \sqrt{k_{y} k_{v}} p_{w f}}
\end{aligned}
$$




\section{RESULTS AND DISCUSSIONS}

A number of calculations have been conducted to investigate the relative importance of frictional wellbore pressure drops and pressure drops across perforation tunnels as compared to pressure drawdown for a horizontal oil producer. The criteria discussed above have been applied to determine whether it is necessary to include completion details in a reservoir simulation study.

For reference, the base parameters used in the study are listed in the table below (Table 1):

Table 1. Base parameters used in the sensitivity study.

\begin{tabular}{|c|c|c|}
\hline Parameter & Value & Unit \\
\hline Fluid Density, $\rho$ & 50 & $(\mathrm{lbm} / \mathrm{ft} 3)$ \\
\hline Fluid Viscosity, $\mu$ & 1 & $(c p)$ \\
\hline Fluid FVF, B & 1.25 & $(\mathrm{rb} / \mathrm{STB})$ \\
\hline Horizontal $\mathrm{x}$-Dimension, $2 \mathrm{x}_{\mathrm{e}}$ & 2640 & $(f t)$ \\
\hline Horizontal y-Dimension, $2 \mathrm{y}_{\mathrm{e}}$ & 2640 & $(f t)$ \\
\hline Reservoir Thickness, $\mathrm{h}$ & 50 & $(f t)$ \\
\hline Horizontal Permeability, $\mathrm{k}_{\mathrm{x}}$ & 100 & $(m D)$ \\
\hline Horizontal Permeability, $\mathrm{k}_{\mathrm{y}}$ & 100 & $(m D)$ \\
\hline Vertical Permeability, $\mathrm{k}_{\mathrm{v}}$ & 50 & $(m D)$ \\
\hline Constant Pressure Boundary? (Y or N) & $\mathbf{N}$ & $(-)$ \\
\hline Well Length, L & 2000 & $(f t)$ \\
\hline Wellbore Diameter, $2 \mathrm{r}_{\mathrm{w}}$ & 0.73 & $(f t)$ \\
\hline Well Center in $\mathrm{x}, \mathrm{x}_{\mathrm{w}}$ & 1320 & $(f t)$ \\
\hline Well Center in $\mathrm{y}, \mathrm{y}_{\mathrm{w}}$ & 1320 & $(f t)$ \\
\hline Well Center in $\mathrm{z}, \mathrm{z}_{\mathrm{w}}$ & 25 & $(f t)$ \\
\hline Mechanical Skin, s & $\mathbf{0}$ & $(-)$ \\
\hline non-Darcy Coefficient, D & 0.0002 & $(1 / M s c f)$ \\
\hline Absolute Wellbore Roughness, $\varepsilon$ & 0.00006 & $(f t)$ \\
\hline Perforation Exists in Completion ? (Y or $\mathrm{N})$ & $\mathbf{Y}$ & $(-)$ \\
\hline Perforation Density, $\mathrm{n}_{\mathrm{p}}$ & 12 & $($ shot $/ f t)$ \\
\hline Perforation Diameter, $\mathrm{d}_{\mathrm{p}}$ & 0.25 & (inch) \\
\hline Perforation Tunnel Length, $\mathrm{L}_{\mathrm{p}}$ & 2 & $(f t)$ \\
\hline Gravel/sand inside the Perforation Tunnel? & $\mathbf{Y}$ & $(-)$ \\
\hline Gravel/sand Permeability, $\mathrm{k}_{\mathrm{p}}$ & 40 & (Darcy) \\
\hline Pressure Drawdown, $\Delta \mathrm{p}$ & 100 & (psi) \\
\hline
\end{tabular}

With the base parameters, the predicted wellbore pressure drop is found to be $6.05 \%$ of the pressure drawdown, while the calculated pressure drop across a perforation tunnel is around $18.75 \%$ of the drawdown. Hence, for this case it appears necessary to incorporate completion details in a res- ervoir simulation model to capture all the major pressure drops occurring around the wellbore and thus accurately predict the well performance from the simulation study.

Sensitivity studies have also been performed for both oil and gas wells to assess the needs to incorporate the completion details in a reservoir simulation study. In this section, results for the sensitivity investigation for a $2000 \mathrm{ft}$ long horizontal oil producer will be presented and discussed.

The first parameter evaluated is horizontal permeability (Fig. 7). When the horizontal permeability increases, well production rate also increases at a fixed pressure drawdown. As a result, the fluid flow along the wellbore and perforation tunnels also increases; therefore, the pressure drop along the perforation tunnels and the wellbore pressure drops become larger. At $50 \mathrm{mD}$, the ratio of pressure drop across perforation tunnels over pressure drawdown $\left({ }^{\Delta P_{P T}} / \Delta P\right.$ ) is $9 \%$, whereas the ratio of the wellbore pressure drop over the same pressure drawdown $\left({ }^{\Delta P_{w}} / \Delta P\right.$ ) is around $2 \%$. Therefore, completion details may not be required in setting up a reservoir simulation model. However, at $500 \mathrm{mD}$, both ratios would jump to $120 \%$ and $117 \%$, respectively. In other words, all the other parameters fixed, the higher the reservoir permeability, the larger the ${ }^{\Delta P_{P T}} / \Delta P$ and $\Delta P_{W} / \Delta P$, and the stronger needs to incorporate completion details in a reservoir simulation study.

The impact of reservoir heterogeneity is less significant as compared to those of the horizontal permeability (Fig. 8). When the vertical to horizontal permeability ratio $\left(\mathrm{k}_{\mathrm{v}} / \mathrm{k}_{\mathrm{h}}\right)$ varies from 0.05 to 1.0 , the well flow rate would increase from $2256 \mathrm{STB} / \mathrm{d}$ to $3388 \mathrm{STB} / \mathrm{d}$. Correspondingly, the ratio of pressure drops across perforation tunnels over pressure drawdown ( ${ }^{\Delta P_{P T}} / \Delta P$ ) would increase from $13 \%$ to $20 \%$, and the ratio of the wellbore pressure drop over pressure drawdown $\left({ }^{\Delta P_{w}} / \Delta P\right.$ ) would enhance from 3\% to slightly over $6 \%$.

An increase in the horizontal well length tends to reduce the flow along perforation tunnels if perforation density stays the same. Consequently, the impacts of pressure drop along perforation tunnels and the needs to include completion details in a reservoir simulation model would be reduced (Fig. 9). For $500 \mathrm{ft}$ horizontal well, the ratio of pressure drops across perforation tunnels over pressure drawdown $\left({ }^{\triangle P P T} / \triangle P\right.$ ) would be around $25 \%$; for a $2500 \mathrm{ft}$ horizontal well, the ratio would be reduced to around $19 \%$. Note that a minimum of the ratio $(\sim 18.5 \%)$ would be reached when the well length reaches around $1700 \mathrm{ft}$ (Fig. 9). On the other hand, the longer the horizontal well, the higher the ratio of wellbore pressure drop over pressure drawdown $\left(\Delta P_{w} / \Delta P\right)$. When the well length increases to about $2300 \mathrm{ft}$, the ratio of wellbore pressure drop over pressure drawdown ( ${ }^{\Delta P_{w}} / \Delta P$ ) would increase to $10 \%$, where the pressure drop along the wellbore alone becomes important and should not be ignored in the reservoir simulation.

The increase in wellbore size would yield slightly higher well production (Fig. 10). The amount of increase in well production primarily depends on the ratio of frictional wellbore pressure drop and pressure drawdown. When the wellbore diameter is increased from 3 inch to $11 \mathrm{inch}$, production would increase from $3175 \mathrm{STB} / \mathrm{d}$ to about $3350 \mathrm{STB} / \mathrm{d}$ (by around $5 \%$ increase). The increase in the well production rate is minor in this case due to the insignificant pressure 


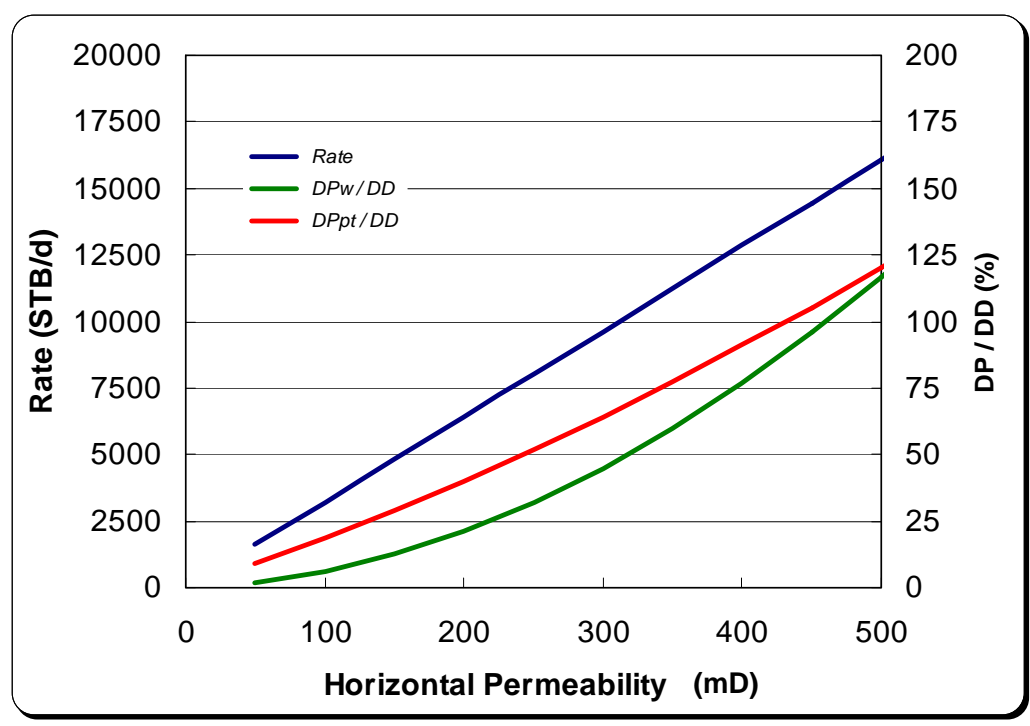

Fig. (7). Impacts of the horizontal permeability.

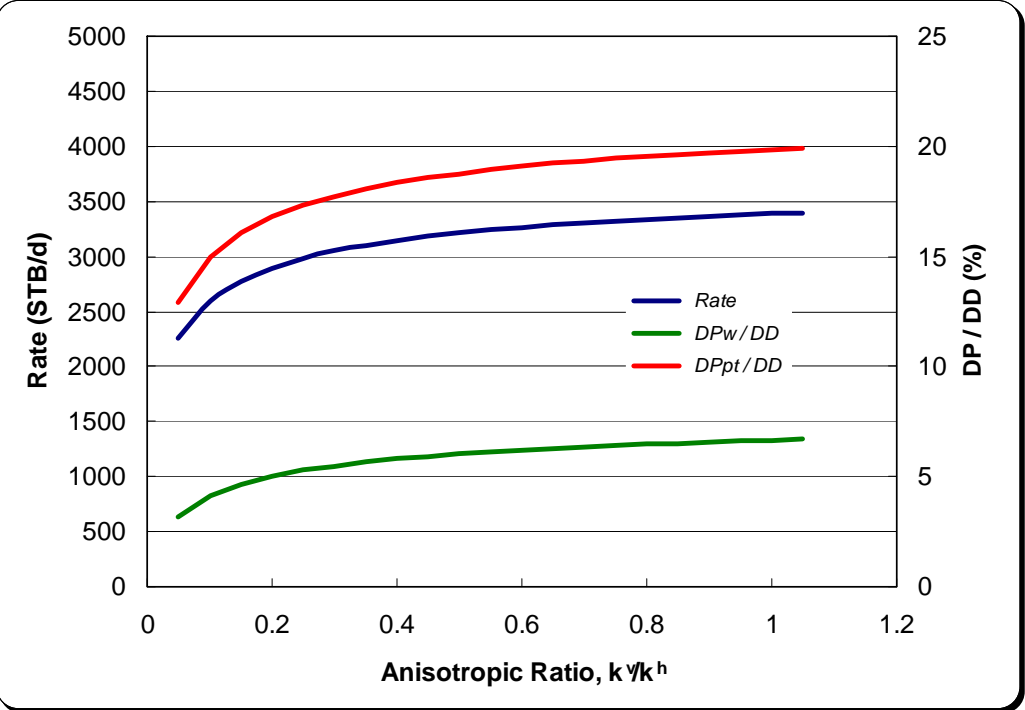

Fig. (8). Impacts of the reservoir anisotropy.

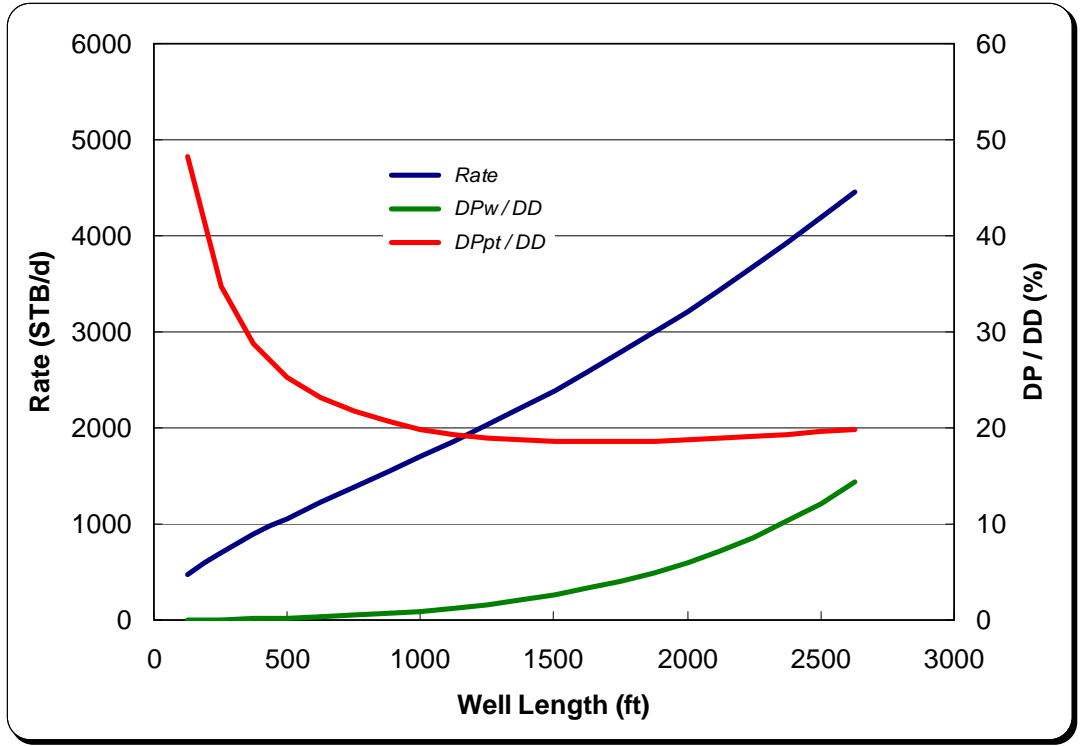

Fig. (9). Impacts of the horizontal well length. 


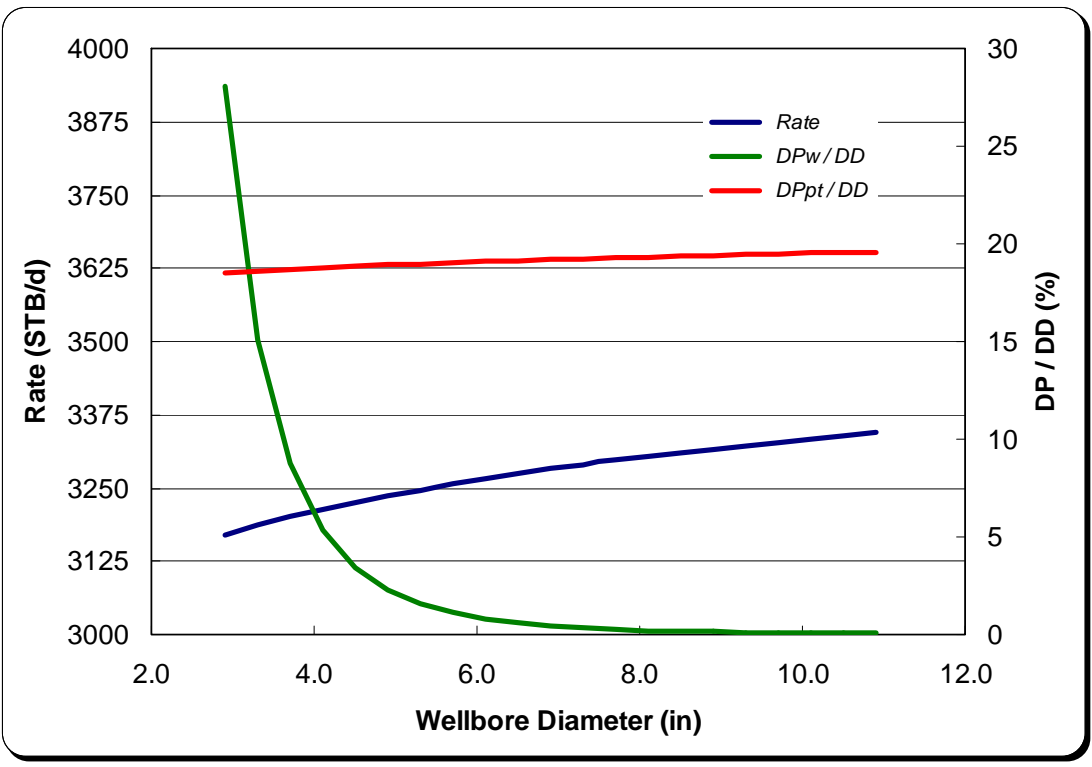

Fig. (10). Impacts of the horizontal wellbore size.

drop along the wellbore. The increase would be higher for high rate oil and gas wells where the frictional pressure drop along a wellbore becomes more significant as compared to pressure drawdown. Also note that the wellbore pressure drop decreases substantially with the increase in wellbore size. That is why large wellbore has recently been introduced in high rate gas wells in several high profile gas developments across the world.

Due to the slight increase in the well production rate, the pressure drops across perforation tunnels maintain almost identical due to the negligible increase in the flow rate along each perforation tunnels (Fig. 10).

Impacts of fluid properties (like fluid viscosity) are not as obvious as the impacts of the other parameters discussed so far (Fig. 11). When the oil viscosity is increased, well production rate would also drop quickly at the specified pressure drawdown, leading to decreased wellbore pressure drops and pressure drops across perforation tunnels. Nevertheless, the relative importance of the pressure drops along perforation tunnels remains high at around $17 \%$ even with the increase of fluid viscosity from $1 \mathrm{cp}$ to $10 \mathrm{cp}$ (Fig. 11).

Increased pressure drawdown would yield higher well production rate. At the same time, both the ratio of pressure drop across perforation tunnels over pressure drawdown $\left({ }^{\triangle P_{P T}} / \Delta P\right.$ ) and the ratio of the wellbore pressure drop over drawdown $\left(\Delta P_{w} / \Delta P\right.$ ) would increase with pressure drawdown (Fig. 12). When the drawdown increases from 50 psi to 500 psi, well production increases proportionally to the drawdown. As a result, more significant impacts of the pressure drops along wellbore and perforation tunnels have been observed (Fig. 12). The ratio of pressure drop across perforation tunnels over pressure drawdown $\left({ }^{\Delta P_{P T}} / \Delta P\right.$ ) would increase by about $6 \%$, i.e., from $18 \%$ to $24 \%$; whereas even more change would be seen in the ratio of the wellbore pressure drop over pressure drawdown $\left(\Delta_{w} / \Delta P\right.$ ), $3 \%$ to $23 \%$, a $20 \%$ jump in the ratio. For the scenario, no matter how much is the pressure drawdown, the sum of the pressure drop along perforation tunnels and pressure drop along the wellbore would be well over the $10 \%$ threshold of the pressure draw- down. Therefore, the completion details must be considered in a reservoir simulation model.

Perforation itself is anticipated to affect more on the pressure drop along perforation tunnels and the ratio of the pressure drop along perforation tunnels over pressure drawdown $\left({ }^{\triangle P_{P T}} / \Delta P\right)$. As clearly demonstrated in Figs. (13-15), well perforation should not pose much influence on well production and wellbore pressure drop. With the increase in perforation density, the fluid flow along each perforation tunnel would decrease and the ratio of the pressure drop along perforation tunnels over pressure drawdown $\left({ }^{\Delta P_{P T}} /{ }_{\Delta P}\right)$ would be reduced (Fig. 13). It has been found that when the effective perforation density falls to 5 shots/ft (due to whatever reason), the flow along each perforation tunnel would be so high that the pressure drop along the perforation tunnel would become as high as $\sim 50 \%$ of the pressure drawdown. When the perforation density is raised to 25 shots $/ \mathrm{ft}$, the ratio of the pressure drop along perforation tunnel over pressure drawdown ( ${ }^{\Delta P_{P T}} / \Delta P$ ) would fall by more than five times to $\sim$ $8 \%$.

In reality, with more and more hydrocarbon is produced from a production well, some of the perforation may be plugged because of scale, sand, hydrates, etc, the effective perforation density would decrease, as a consequence, the pressure drop along each perforation tunnel is expected to increase unless the perforation plugging also leads to significant reduction in well production.

Similar to the impacts of wellbore size on the frictional pressure drop along a wellbore, pressure drops along perforation tunnels also rely on the size of the perforation tunnels, i.e., the perforation diameters (Fig. 14). For typical perforations, the perforation diameter is around 0.25 inch, which would lead to about $19 \%$ of the pressure drawdown along perforation tunnels $\left({ }^{\Delta P_{P T}} / \Delta P=19 \%\right.$ ) for the horizontal oil production well investigated in this study. If the perforation diameter is increased to $0.30 \mathrm{inch},{ }^{\triangle P} P T / \triangle P$ would be reduced to about $13 \%$. On the other hand, if the perforation diameter is changed to 0.2 inch, the ${ }^{\Delta P_{P T}} / \Delta P$ would shoot up to more than $30 \%$. Under the circumstances, the completion details must 


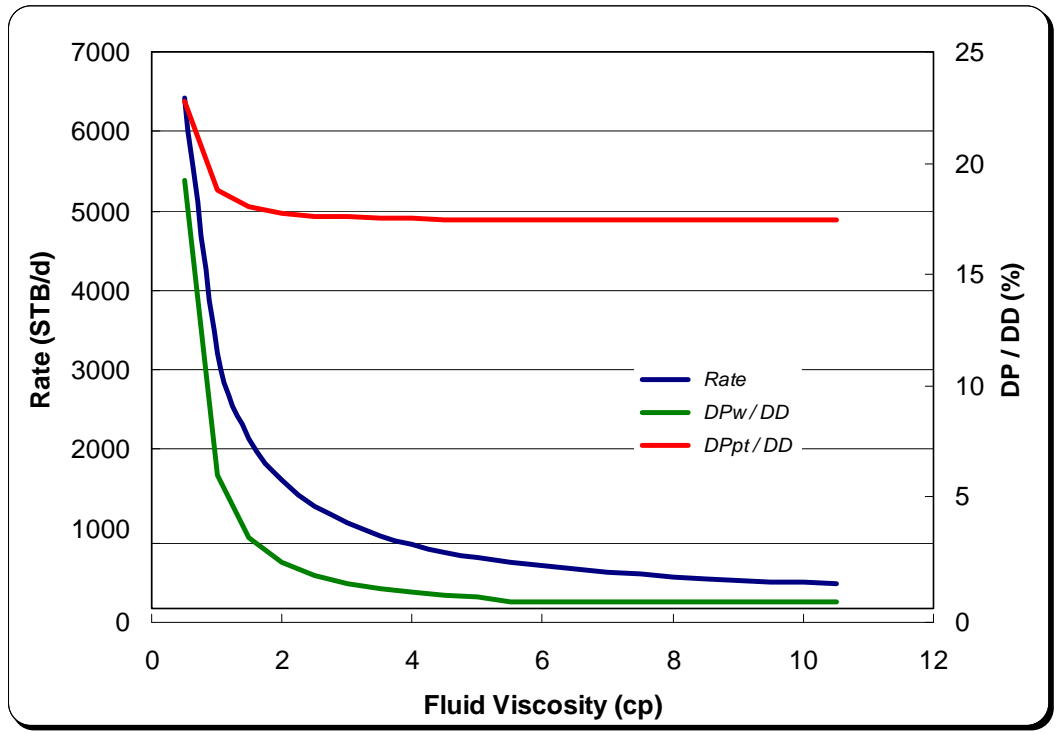

Fig. (11). Impacts of the fluid viscosity.

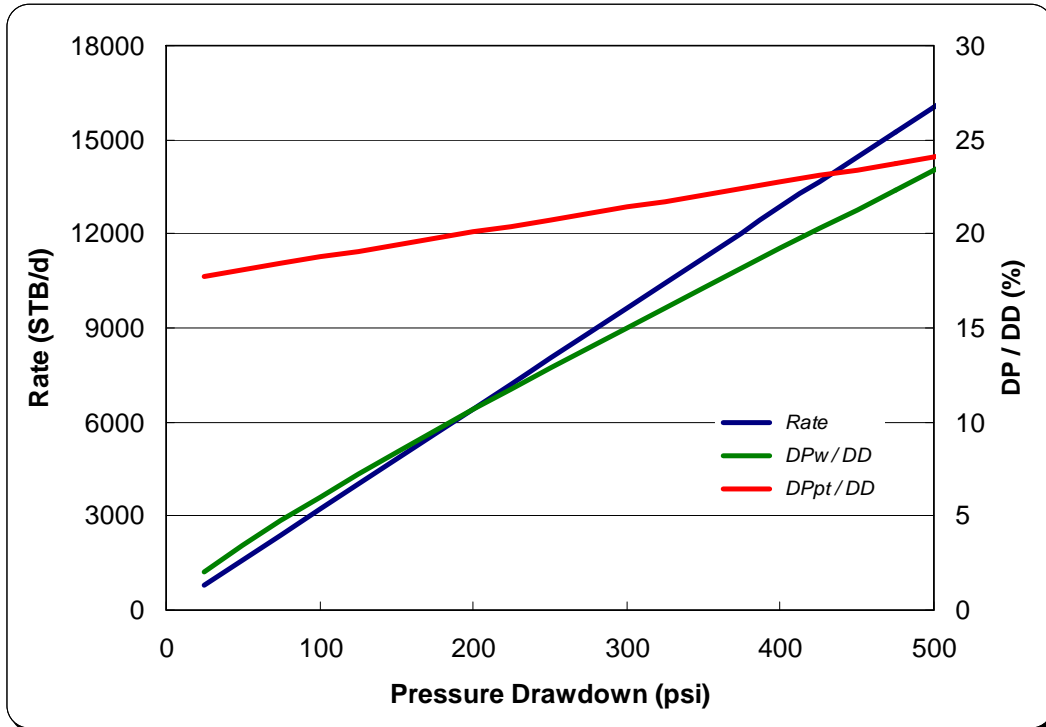

Fig. (12). Impacts of the pressure drawdown.

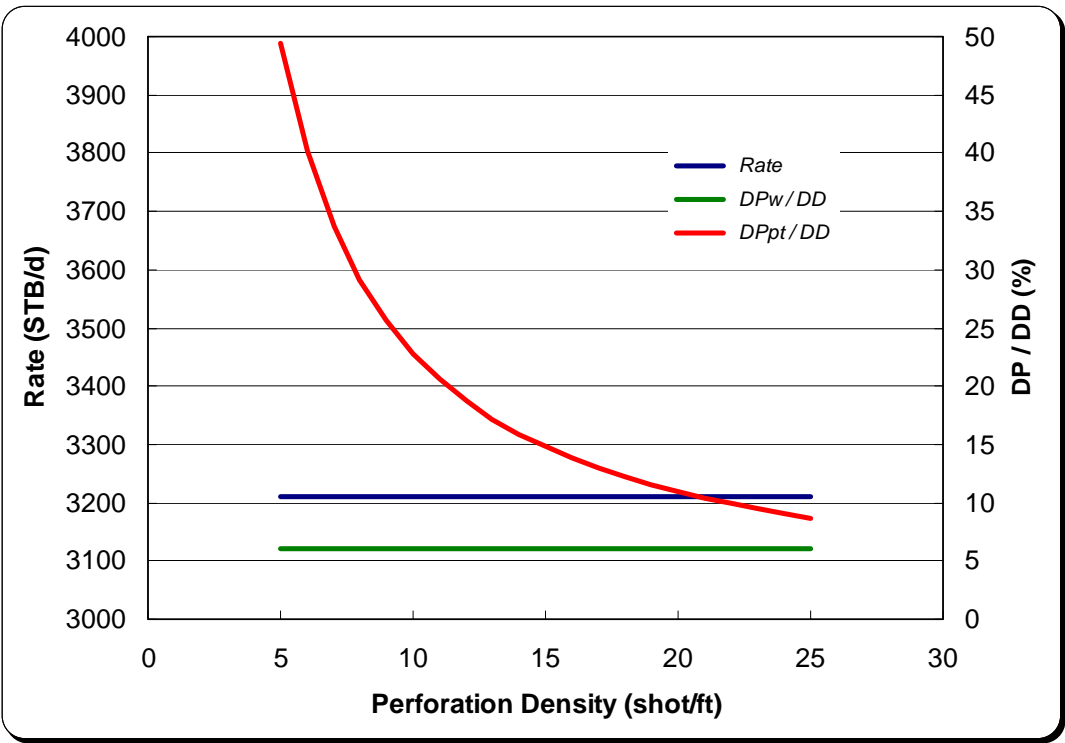

Fig. (13). Impacts of the perforation density. 


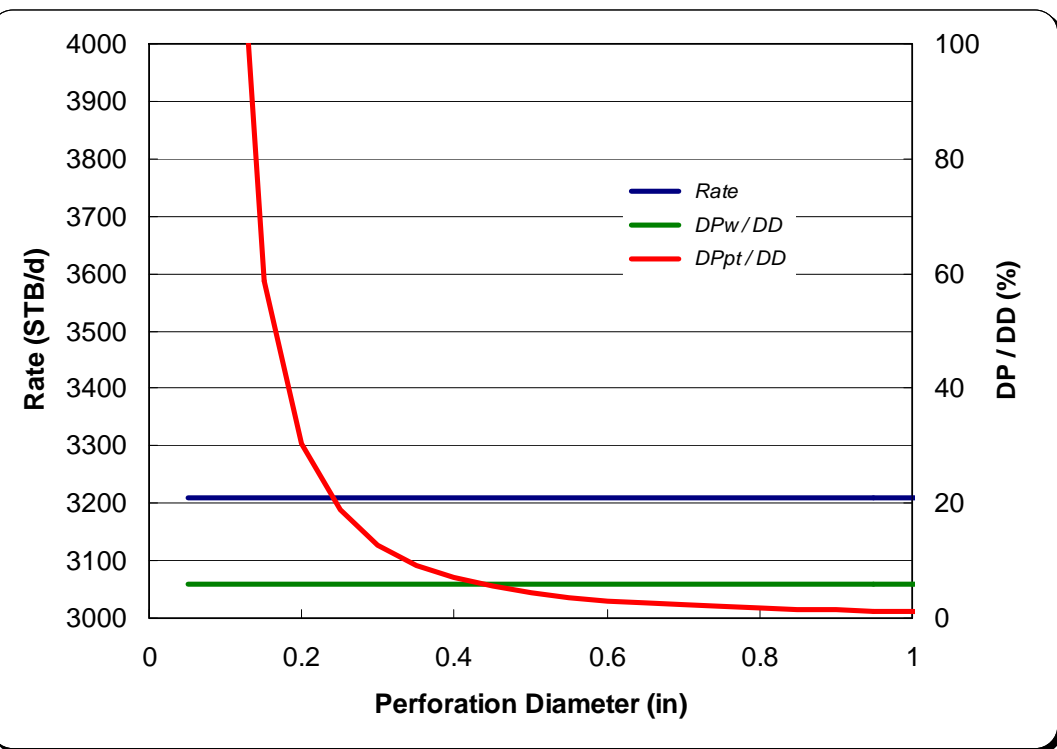

Fig. (14). Impacts of the perforation diameter.

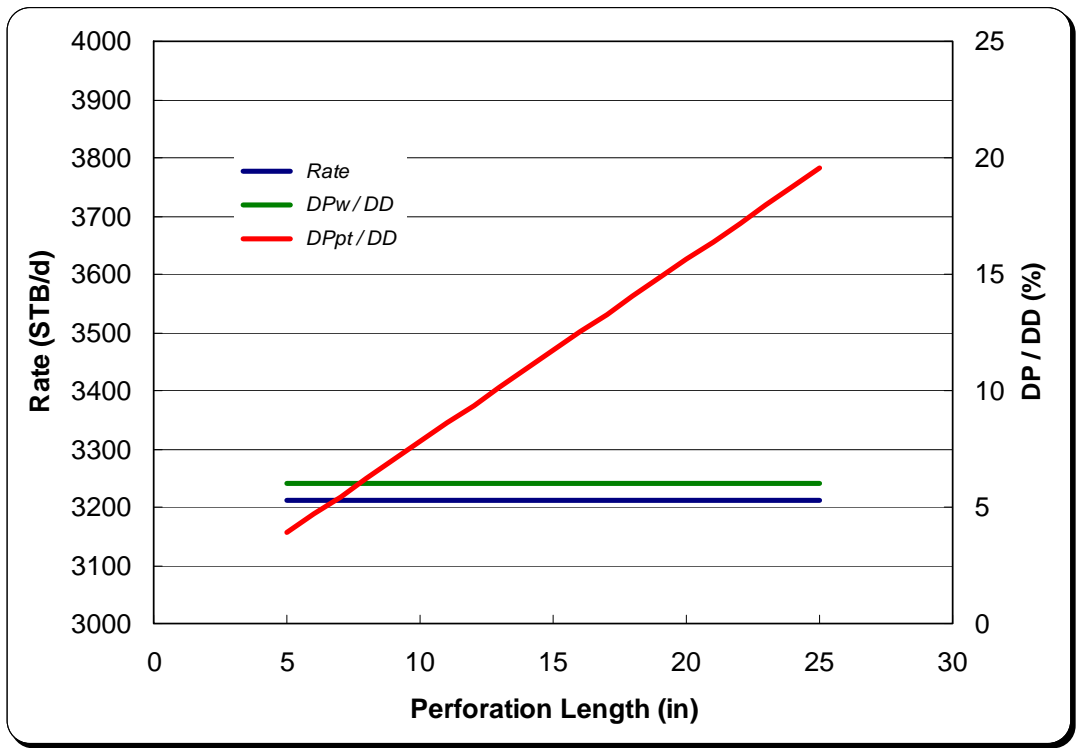

Fig. (15). Impacts of the perforation length.

be included in a reservoir simulation study to avoid significant error in simulation predictions.

No significant impact of perforation geometry (like length and diameter) on well production is anticipated (Figs. 14 and 15). Increase in the length of perforation tunnels yields higher pressure drops along the tunnels and thus a higher ${ }^{\Delta P_{P T}} / \Delta P$ (Fig. 15). Note that $\Delta P_{P T} / \Delta P$ is approximately proportional to the length of the perforation tunnels. When the length of the perforation tunnels changes from 5 inch to 15 inch, the ${ }^{\triangle P_{P T}} /{ }_{\triangle P}$ ratio would increase from $4 \%$ to $\sim 12 \%$.

Finally note that the length of perforation tunnels is normally dependent on the types of completion adopted in a specific well.

\section{CONCLUSION}

Based on the understanding of the fluid flow in a formation, along a wellbore and through perforation tunnels if ex- ist, new equations have been developed to assess the needs for incorporating completion details in a reservoir simulation study. A series of sensitivity studies with different completion options under different flow and reservoir environments have been conducted. Impacts of key parameters like perforation density, perforation diameter, perforation length, wellbore length, wellbore diameter, well completion configuration, well length, reservoir permeability, reservoir heterogeneity, pressure drawdown, etc. have also been evaluated.

\section{NOMENCLATURE}

$\mathrm{A}=$ Wellbore cross-sectional area, $\mathrm{ft}^{2}$

$\mathrm{A}_{1}=$ Horizontal well drainage area in the vertical plane, $\mathrm{ft}^{2}$

$\mathrm{A}_{\mathrm{p}}=$ Cross-sectional area of a perforation tunnel, $\mathrm{ft}^{2}$

$\mathrm{B}_{\mathrm{o}}=$ Formation volume factor for oil, $\mathrm{rb} / \mathrm{STB}$ 

$\mathrm{C}_{\mathrm{H}}=$ Shape factor for a horizontal well
$\mathrm{c}_{\mathrm{t}}=$ Total compressibility, $1 / \mathrm{psi}$
$\mathrm{d}_{\mathrm{p}}=$ Diameter of perforation tunnels, $\mathrm{ft}$
$\mu \quad=\quad$ Fluid viscosity, $\mathrm{cp}$
$\rho=$ Fluid density, $\mathrm{lbm} / \mathrm{ft}^{3}$
$\varphi \quad=\quad$ Fluid potential, psi

$\mathrm{D}=$ Non-Darcy coefficient, $1 /$ (Mscf/day)

$\mathrm{DD}=$ Pressure drawdown, psi

$\mathrm{f}=$ The Fanning friction factor

$\mathrm{g}=$ Acceleration of gravity $\left(32.17405 \mathrm{ft} / \mathrm{sec}^{2}\right.$ in field unit)

$\mathrm{g}_{\mathrm{c}}=$ Conversion factor $\left(32.17405 \mathrm{lbm}-\mathrm{ft} / \mathrm{lbf}-\mathrm{sec}^{2}\right.$ in field unit)

$\mathrm{h}=$ Thickness of the reservoir, $\mathrm{ft}$

$\mathrm{J}_{\mathrm{H}}=$ Productivity of a well, STB/day/psi

$\mathrm{k}_{\mathrm{h}}=$ Horizontal permeability, $\mathrm{mD}$

$\mathrm{k}_{\mathrm{v}}=$ Vertical permeability, $\mathrm{mD}$

$\mathrm{k}_{\mathrm{x}} \quad=$ Permeability in the $\mathrm{x}$-direction, $\mathrm{mD}$

$\mathrm{k}_{\mathrm{y}}=$ Permeability in the y-direction, $\mathrm{mD}$

$\mathrm{k}_{\mathrm{z}} \quad=$ Permeability in the z-direction, $\mathrm{mD}$

$\mathrm{k}_{\mathrm{g}}=$ Gravel permeability in perforation tunnels, Darcy

$\mathrm{L}=$ Length of the horizontal well, $\mathrm{ft}$

$\mathrm{L}_{\mathrm{p}} \quad=$ Length of the perforation tunnel, $\mathrm{ft}$

$\mathrm{n}_{\mathrm{p}}=$ Perforation density, shots $/ \mathrm{ft}$

$\mathrm{p} \quad=$ Pressure, $\mathrm{psi}$

$\mathrm{p}_{\mathrm{r}}=$ Reservoir pressure, $\mathrm{psi}$

$\mathrm{p}_{\mathrm{wf}}=$ Bottomhole wellbore pressure, $\mathrm{psi}$

$\mathrm{Q}=$ Well production rate, STB/day for oil well and Mscf/day for gas well

$\mathrm{q}=$ Fluid flow through each perforation tunnel $\left[=\mathrm{QB} /\left(\mathrm{Ln}_{\mathrm{p}}\right)\right], \mathrm{bbl} / \mathrm{day}$,

$\mathrm{R}_{\mathrm{e}} \quad=$ The Reynolds number

$\mathrm{r}_{\mathrm{eh}}=$ Drainage radius of a horizontal well, $\mathrm{ft}$

$\mathrm{r}_{\mathrm{w}}=$ Wellbore radius, $\mathrm{ft}$

$\mathrm{S}_{\mathrm{R}} \quad=$ Skin factor due to partial penetration in the aerial plane

$\mathrm{T}=$ Temperature, ${ }^{\circ} \mathrm{R}$

$\mathrm{x}_{\mathrm{e}}=\mathrm{A}$ half of the reservoir dimension in the $\mathrm{x}-$ direction, $\mathrm{ft}$

$\mathrm{y}_{\mathrm{e}}=\mathrm{A}$ half of the reservoir dimension in the $\mathrm{y}-$ direction, $\mathrm{ft}$

$\mathrm{Z}=$ Gas compressibility factor

$\Delta \mathrm{p}=$ Pressure drawdown, $\mathrm{psi}$

$\Delta \mathrm{p}_{\mathrm{w}}=$ Frictional wellbore pressure drop, psi

$\Delta \mathrm{p}_{\mathrm{pt}}=$ Pressure drop across a perforation tunnel, psi

$\beta=$ The Forchheimer coefficient, $1 / \mathrm{ft}$

$\gamma_{\mathrm{g}}=$ Gas specific gravity

$\varepsilon \quad=\quad$ Absolute pipe roughness, $\mathrm{ft}$

\section{CONFLICT OF INTEREST}

The author confirms that this article content has no conflict of interest.

\section{ACKNOWLEDGEMENTS}

Declared none.

\section{REFERENCES}

[1] L.B. Ouyang, W.S. Huang, and R. Dickerson, "Efficient cost saving through an appropriate completion design," In: SPE Western Regional/AAPG Pacific Section/GSA Cordilleran Section Joint Meeting, Anchorage, Alaska: USA, 2006.

[2] L.B. Ouyang, "Quantifying non-darcy effects on the productivity of a cased-hole frac pack (CHFP) well," In: SPE Annual Technical Conference and Exhibition, Anaheim, California, USA, 2007.

[3] K. Aziz, and A. Settari, "Petroleum Reservoir Simulation," Elsevier Applied Science Publishers, New York City, 1979.

[4] S.D. Joshi, "A review of horizontal well and drainhole technology," In: SPE Annual Technical Conference and Exhibition, Dallas, TX: USA, 1987.

[5] S.D. Joshi, "Augmentation of well productivity using slant and horizontal wells," Journal of Petroleum Technology, vol. 40, no. 6, pp. 729-739, 1988.

[6] J.P. Borisov, "Oil production using horizontal and multiple deviation wells," Nedra, Moscow, 1964. In: J. Strauss, S.D. Joshi, Eds., Phillips Petroleum Co., the R\&D Library Translation, Bartlesville: Oklahoma, 1984

[7] F.M. Giger, "Reduction du nombre de puits par L'utilisation de forrages horizontaux," Oil \& Gas Science and Technology IFP, vol. 38, no. 3, pp. 351-360, 1983.

[8] F.M Giger, L.H. Reiss, and A.P. Jourdan, "The reservoir engineering aspect of horizontal drilling," In: SPE 59 $9^{\text {th }}$ Annual Technical Conference \& Exhibition, Houston: Texas, 1984.

[9] G.I. Renard, and J.M. Dupuy, "Influence of formation damage on the flow efficiency of horizontal wells," In: SPE International Formation Damage Control Symposium, Lafayette: Louisiana, 1990.

[10] D.K. Babu, and A.S. Odeh, "Productivity of a horizontal well," In: SPE Reservoir Engineering, 1989, pp. 417-421.

[11] S.D. Joshi, "Horizontal well technology," PennWell Publishing Co., Tulsa, OK, 1991.

[12] P.N. Mutalik, S.P. Godbole, and S.D. Joshi, "Effect of drainage area shapes on horizontal well productivity," In: SPE $63^{\text {rd }}$ Annual Technical Conference \& Exhibition, Houston: Texas, 1988.

[13] F.J. Kuchuk, P.A. Goode, B.W. Brice, D.W. Sherrard, and R.K.M. Thambynayagam, "Pressure transient analysis and inflow performance for horizontal wells," In: SPE $63^{\text {rd }}$ Annual Technical Conference \& Exhibition, Houston: Texas, 1988.

[14] A. Firoozabadi, and D.L. Katz, "An analysis of hig-velocity gas flow through porous media," Journal of Petroleum Technology, vol. 31, no. 2, pp. 211-216, 1979.

[15] T. Unneland, "An improved model for predicting high-rate casedhole gravel-pack well performance," In: SPE European Formation Damage Conference, Hague: The Netherlands, 1999.

[16] C.F. Colebrook, and C.M. White, "Experiments with fluid friction in roughened pipes," In: Royal Society of London, $161 \mathrm{~A}$ (906), pp. 367-381, 1937.

[17] L.B. Ouyang, and K. Aziz, "Steady-state gas flow in pipes," Journal of Petroleum Science \& Engineering, vol. 14, no. 3-4, pp. $137-$ 158, 1996. 
[18] T.V. Nguyen, "Experimental study of non-darcy flow through perforations," In: $61^{\text {st }}$ SPE Annual Technical Conference and Exhibition, New Orleans: LA, 1986.

[19] R.J. Saucier, "Considerations in gravel-pack design," Journal of Petroleum Technology, vol. 26, no. 2, pp. 205-212, 1974.
[20] H.D. Lopez-Hernandez, P. Valko, and T.T. Pham, "Optimum fracture treatment design minimizes the impact of non-darcy flow effects," In: 2004 SPE Annual Technical Conference \& Exhibition, Houston: Texas, 2004

Received: May 13, 2014

Revised: September 23, 2014

Accepted: November 09, 2014

(C) Liang-Biao Ouyang; Licensee Bentham Open.

This is an open access article licensed under the terms of the Creative Commons Attribution Non-Commercial License (http://creativecommons.org/licenses/by-nc/3.0/) which permits unrestricted, non-commercial use, distribution and reproduction in any medium, provided the work is properly cited. 